\title{
Redefining the $\beta$-Phase Stability in Ti-Nb-Zr Alloys for Alloy Design and Microstructural Prediction
}

\author{
A. MEHJABEEN ${ }^{1}$ W. XU, ${ }^{1,2}$ D. QIU, ${ }^{1}$ and M. QIAN (1) ${ }^{1,3}$ \\ 1.-School of Engineering, Centre for Additive Manufacturing, RMIT University, Melbourne, \\ VIC 3000, Australia. 2.-School of Engineering, Macquarie University, Sydney, NSW 2109, \\ Australia. 3.-e-mail: ma.qian@rmit.edu.au
}

$\beta$-Phase stability is a key consideration for the design of $\beta$-titanium $(\beta$-Ti) alloys and subsequent heat treatment and/or thermo-mechanical processing. The concept of the Mo equivalence (Mo-Eq), proposed by Molchanova (Phase diagrams of titanium alloys, 1965), has been commonly used as a general guideline to gauge the stability of a $\beta$-Ti alloy. A critical literature review has shown that all four existing Mo-Eq expressions deviate substantially from experimental observations and the well-established $d$-electron theory in predicting the $\beta$-phase stability of Ti-Nb-Zr alloys. The reasons are that existing Mo-Eq expressions either completely neglect or significantly overestimate the $\beta$-stabilizing effect of Zr. In this study, a new Mo-Eq expression, i.e., (Mo-Eq) $)_{\text {Ti- }}$ $\mathrm{Nb}-\mathrm{Zr}=0.238 \mathrm{Nb}($ wt.\%) $+0.11 \mathrm{Zr}($ wt.\% $)+0.97$, has been defined for $\mathrm{Ti}-\mathrm{Nb}-\mathrm{Zr}$ alloys in order to properly address the $\beta$-stabilizing effect of Zr. This new MoEq expression showed proven consistency with both experimental observations and the $d$-electron theory in predicting the $\beta$-phase stability of various $\mathrm{Ti}-\mathrm{Nb}-\mathrm{Zr}$ alloys. With necessary modifications, the approach developed is expected to be also applicable to the assessment of the $\beta$-phase stability in other Zr-containing Ti alloys.

\section{INTRODUCTION}

$\beta$-Titanium ( $\beta$-Ti) alloys that are free from vana$\operatorname{dium}(\mathrm{V})$, nickel $(\mathrm{Ni})$ and aluminium $(\mathrm{Al})$ are one of the most promising groups of metallic biomaterials for orthopaedic applications. By definition, $\beta$-Ti alloys refer to those which contain sufficient $\beta$-stabilizing element(s) to enable the $\beta$-phase to be retained in a metastable condition by water quenching. ${ }^{1}$ They are generally divided into metastable (age-hardenable) and stable $\beta$-Ti alloys (not age-hardenable). ${ }^{2}$ The critical minimum amount of $\beta$-stabilizers needed to retain $100 \% \beta$-phase on water quenching is denoted as $\beta_{\mathrm{c}}$, while the minimum content of $\beta$-stabilizers needed to form stable $\beta$-Ti alloys is referred to as $\beta_{\mathrm{s}}$. Metastable $\beta$-Ti alloys are those that fall in between $\beta_{\mathrm{c}}$ and $\beta_{\mathrm{s}}$, within which $\alpha$ can precipitate upon ageing. As the values of $\beta_{\mathrm{c}}$ and $\beta_{\mathrm{s}}$ depend on alloy chemistry, a parameter known as the Mo equivalent (Mo-Eq) has been defined and commonly used as a general guideline to assess the $\beta$-phase stability of a Ti alloy for both alloy design and processing. ${ }^{3-5}$ It is therefore an important design parameter for Ti alloys. This paper first examines all existing Mo-Eq expressions and then focuses on the development of a new Mo-Eq equation proposed specifically for the $\mathrm{Ti}-\mathrm{Nb}-\mathrm{Zr}$ system. This is followed by a detailed experimental assessment and comparison with Morinaga's $d$-electron theory for alloy design.

\section{EXISTING MO-EQ EXPRESSIONS AND THEIR DEFICIENCIES}

The concept of the Mo equivalence was proposed by Molchanova [Phase diagrams of titanium alloys (Figs. 193 and 194, p. 158)], ${ }^{3}$ which was a translation from Atlas Diagramm Sostoyaniya Titanovykh Splavov (Israel Program for Scientific Translations, Jerusalem, 1965). Boyer et $\mathrm{al}^{4}$ presented the data shown in Fig. 193 of Ref. 3 as the Mo equivalence of a titanium alloy in the well-known Materials properties handbook: titanium alloys (1994) in the following form: 


$$
\begin{aligned}
&(\text { Mo-Eq })^{\text {Molchanova }[3]} \\
&= 1.0(\% \mathrm{Mo})+0.2(\% \mathrm{Ta})+0.28(\% \mathrm{Nb}) \\
&+0.4(\% \mathrm{~W})+0.67(\% \mathrm{~V})+1.25(\% \mathrm{Cr}) \\
&+1.25(\% \mathrm{Ni})+1.7(\% \mathrm{Mn})+1.7(\% \mathrm{Co}) \\
&+2.5(\% \mathrm{Fe})
\end{aligned}
$$

Bania $^{5}$ then further discussed the Mo-Eq concept and expressed it in the form of Eq. 2 in which the prefix coefficient of each $\beta$-stabilizer represents the ratio of the $\beta_{\mathrm{c}}$ value of Mo (i.e., $10 \mathrm{wt} . \%$ ) to that of respective $\beta$-stabilizer. As an $\alpha$-stabilizer, $\mathrm{Al}$ is also included to show its opposing effect when it is present in a $\beta$-Ti alloy.

$$
\begin{aligned}
&(\mathrm{Mo}-\mathrm{Eq})^{\text {Bania }[5]} \\
&= 1.0(\% \mathrm{Mo})+0.67(\% \mathrm{~V})+0.44(\% \mathrm{~W}) \\
&+0.28(\% \mathrm{Nb})+0.22(\% \mathrm{Ta})+2.9(\% \mathrm{Fe}) \\
&+1.6(\% \mathrm{Cr})+0.77(\% \mathrm{Cu})+1.11(\% \mathrm{Ni}) \\
&+1.43(\% \mathrm{Co})+1.54(\% \mathrm{Mn})-1.0(\% \mathrm{Al})
\end{aligned}
$$

Equation 2 overrides the original Eq. 1 as a commonly used expression to estimate the Mo-Eq of a Ti alloy. Apart from Eq. 2, three other expressions for Mo-Eq have also been proposed, ${ }^{6-8}$ namely:

$$
\begin{aligned}
(\mathrm{Mo}-\mathrm{Eq})^{\mathrm{Zhou}[6]} & \\
= & 1.0(\% \mathrm{Mo})+0.74(\% \mathrm{~V})+0.5(\% \mathrm{~W})+0.39(\% \mathrm{Nb}) \\
& +0.28(\% \mathrm{Ta})+2.2(\% \mathrm{Fe})+1.69(\% \mathrm{Cr})+0.85(\% \mathrm{Cu}) \\
& +1.22(\% \mathrm{Ni})+1.57(\% \mathrm{Co})+1.69(\% \mathrm{Mn})
\end{aligned}
$$

$$
\begin{aligned}
(\mathrm{Mo}-\mathrm{Eq})^{\mathrm{Mo}[7]} \\
=1.0(\% \mathrm{Mo})+0.73(\% \mathrm{~V})+0.5(\% \mathrm{~W})+0.31(\% \mathrm{Nb}) \\
+0.24(\% \mathrm{Ta})+2(\% \mathrm{Fe})+1.69(\% \mathrm{Cr}) \\
+1.29(\% \mathrm{Ni})+1.16(\% \mathrm{Co})+1.69(\% \mathrm{Mn})
\end{aligned}
$$

and

$$
\begin{aligned}
& (\text { Mo-Eq })^{\text {Wang }[8]} \\
& =1.0(\% \mathrm{Mo})+1.25(\% \mathrm{~V})+0.59(\% \mathrm{~W})+0.28(\% \mathrm{Nb}) \\
& \quad+0.22(\% \mathrm{Ta})+1.93(\% \mathrm{Fe})+1.84(\% \mathrm{Cr})+1.5(\% \mathrm{Cu}) \\
& +2.46(\% \mathrm{Ni})+2.67(\% \mathrm{Co})+2.26(\% \mathrm{Mn})+3.01(\% \mathrm{Si}) \\
& +0.3(\% \mathrm{Sn})+0.47(\% \mathrm{Zr})-1.47(\% \mathrm{Al})
\end{aligned}
$$

Equations 2-4 are similar and were all formulated on the basis of experimental data, where $\mathrm{Zr}$ was treated as a neutral element and therefore excluded. It should be pointed out that no information was given about the sample size used in the water-quenching experiments, which affects the resultant microstructure. However, Eq. 3 considered that the $\beta_{\mathrm{c}}$ value of Mo should be 11 (rather than 10), which was also mentioned in Ref. 3 . The slight difference between Eqs. 2, 3 and 4 resulted from experimental and analytical errors. In contrast, Eq. 5 combines both experimental and phase diagram data. For example, the coefficients for $\mathrm{Nb}$

\begin{tabular}{|c|c|c|c|c|c|c|c|}
\hline at.\% & wt.\% & $\begin{array}{c}\text { Phases } \\
\text { (water-quenched) }\end{array}$ & $\begin{array}{c}\text { Equation } \\
2\end{array}$ & $\begin{array}{c}\text { Equation } \\
\mathbf{3}\end{array}$ & $\underset{4}{\text { Equation }}$ & $\begin{array}{c}\text { Equation } \\
5\end{array}$ & $\begin{array}{c}\text { New Mo-Eq } \\
\text { by Eq. } 7\end{array}$ \\
\hline $\mathrm{Ti}-12 \mathrm{Nb}-30 \mathrm{Zr}$ & $\mathrm{Ti}-16.82 \mathrm{Nb}-41.29 \mathrm{Zr}$ & $\alpha^{\prime \prime}, \mathrm{b}$ & 4.71 & 6.56 & 5.21 & 24.12 & 9.5 \\
\hline Ti-14Nb-30Zr & Ti-19.4Nb-40.7Zr & $\beta$ & 5.430 & 7.57 & 6.01 & 24.56 & 10.1 \\
\hline $\mathrm{Ti}-8 \mathrm{Nb}-46 \mathrm{Zr}$ & $\mathrm{Ti}-10.4 \mathrm{Nb}-58.8 \mathrm{Zr}$ & $\alpha^{\prime \prime}, \mathrm{b}$ & 2.91 & 4.06 & 3.22 & 30.55 & 9.9 \\
\hline Ti-10Nb-45Zr & Ti-13Nb-57.1Zr & $\beta$ & 3.64 & 5.07 & 4.03 & 30.48 & 10.1 \\
\hline $\mathrm{Ti}-20.9 \mathrm{Nb}-9 \mathrm{Zr}$ & $\mathrm{Ti}-31.7 \mathrm{Nb}-13.4 \mathrm{Zr}$ & $\alpha^{\prime \prime}, \mathrm{b}$ & 8.88 & 12.36 & 9.83 & 15.17 & 9.99 \\
\hline $\mathrm{Ti}-20.2 \mathrm{Nb}-12 \mathrm{Zr}$ & Ti-30.18Nb-17.6Zr & $\beta$ & 8.45 & 11.77 & 9.36 & 16.72 & 10.1 \\
\hline $\mathrm{Ti}-22 \mathrm{Nb}-4 \mathrm{Zr}$ & $\mathrm{Ti}-34.4 \mathrm{Nb}-6.13 \mathrm{Zr}$ & $\beta$ & 9.63 & 13.42 & 10.66 & 12.51 & 9.8 \\
\hline $\mathrm{Ti}-22 \mathrm{Nb}-6 \mathrm{Zr}$ & Ti-33.9Nb-9.1Zr & $\beta$ & 9.49 & 13.22 & 10.51 & 13.77 & 10 \\
\hline Ti-22Nb-8Zr & $\mathrm{Ti}-33.4 \mathrm{Nb}-11.92 \mathrm{Zr}$ & $\beta$ & 9.35 & 13.03 & 10.35 & 14.95 & 10.2 \\
\hline
\end{tabular}
and Ta were taken from Eq. 2, while the coefficient for $\mathrm{Zr}$ was derived from the $\mathrm{Ti}-\mathrm{Zr}$ phase diagram. ${ }^{8}$ As a result, $\mathrm{Zr}$ was treated as a $\beta$-stabilizer that is more potent than $\mathrm{Nb}(0.28)$ and $\mathrm{Ta}(0.22)$, but no experimental support was given. Limited evidence suggests $^{9,10}$ that the $\beta$-stabilizing effect of $\mathrm{Zr}$ depends on the quantity of other $\beta$-stabilizers present in the alloy.

Table I summarizes nine different $\mathrm{Ti}-\mathrm{Nb}-\mathrm{Zr}$ alloys reported in the literature with identified phase constituents in the water-quenched state. 9,11 They provide an experimental basis for a detailed assessment of Eqs. 2 and 5. As can be seen from Table I, despite the high Mo-Eq values predicted by Eq. 5, e.g., 24.12 for Ti-12Nb-30Zr (at.\%), $\alpha^{\prime \prime}$-martensite still forms on water quenching. In other words, Eq. 5 significantly overestimates the $\beta$-stabilizing effect of the alloying elements in these alloys. With

Table I. Metastable $\beta$-region for Ti-Nb-Zr alloy systems and their Mo-Eq ${ }^{9,11}$

Alloy compositions

Mo-Eq values by existing expressions

(wt.\%) 
regards to Eq. 2, it substantially underestimates the overall $\beta$-stabilizing effect of the alloying elements in Ti-Nb-Zr alloys. For example, Eq. 2 predicts Mo-Eq values of 3.64 and 5.43 for Ti-10Nb$45 \mathrm{Zr}$ (at.\%) and $\mathrm{Ti}-14 \mathrm{Nb}-30 \mathrm{Zr}$ (at.\%), respectively, which are much lower than 10. However, the $\beta$-phase was fully retained in both alloys upon water quenching. Equations 2 and 4 offer similar predictions, while Eq. 3 also shows a serious underestimation of the $\beta$-stabilizing effect. For instance, the Mo-Eq of Ti-14Nb-30Zr (at.\%) is predicted to be 7.57 but full $\beta$ phase is retained. So is the case for Ti-10Nb-45Zr (at.\%), where Mo-Eq $=5.07$ but full $\beta$ phase is retained. On the other hand, Eq. 3 overestimates the $\beta$-stabilizing effect in Ti-20.9Nb-9Zr (at.\%) (clear formation of $\alpha^{\prime \prime}$, although Mo-Eq = 12.36). In summary, none of the existing Mo-Eq equations offers predictions that are consistent with experimental observations for $\mathrm{Ti}-\mathrm{Nb}-\mathrm{Zr}$ alloys. In addition, when all these predictions based on Eqs. 2-5 are compared with the $d$-electron theory diagram, there is also substantial inconsistency.

\section{NEW MO-EQ EXPRESSION FOR TI-NB-ZR ALLOYS}

We first determine the Mo-Eq coefficient of $\mathrm{Nb}$. Three different values were used previously in Eqs. 2-5, namely, 0.28\%, 0.31\% and 0.39\%. Recent experimental work has defined that the $\beta_{\mathrm{c}}$ value for Ti-Nb binary alloys is 42 wt. $\%{ }^{12}$ Consequently, the Mo-Eq coefficient of $\mathrm{Nb}$ can be defined as

$$
\psi=(10 / 42)=0.238
$$

We then need to properly consider the $\beta$-stabilizing effect of Zr. As can be seen from Table I, a small increase (e.g., 1-3 at.\%) in the content of $\mathrm{Zr}$ or $\mathrm{Nb}+\mathrm{Zr}$ can change the phase constituents from $\alpha^{\prime \prime}+\beta$ to single $\beta$ under water-quenching conditions. For instance, a single $\beta$-phase was retained in the $\mathrm{Ti}-22 \mathrm{Nb}-4 \mathrm{Zr}$ (at.\%) alloy but not in the Ti-22Nb-

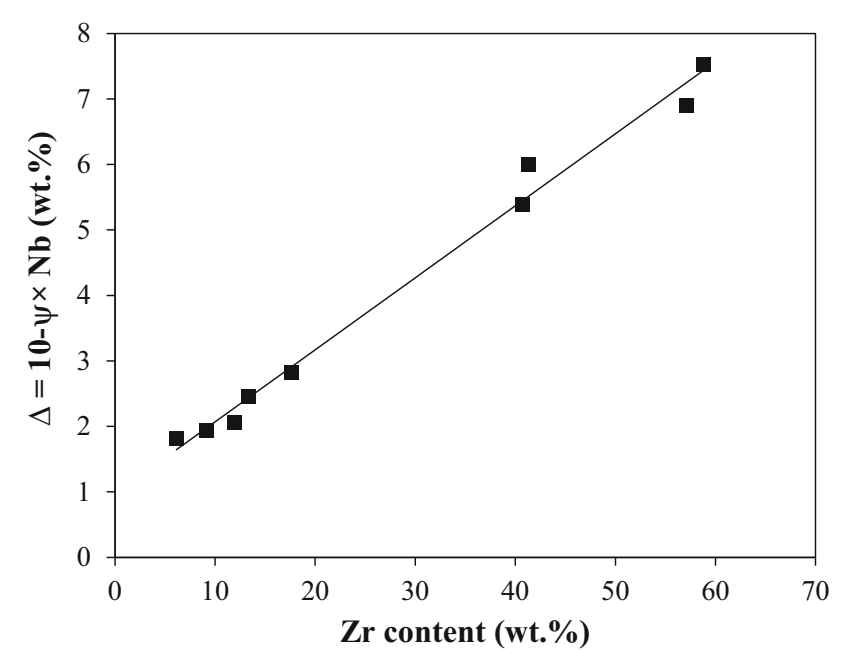

Fig. 1. Dependence of the quantity of $\Delta=10-\psi \times \mathrm{Nb}$ (wt.\%) on $\mathrm{Zr}$ content in $\mathrm{Ti}-\mathrm{Nb}-\mathrm{Zr}$ alloys.
2Zr (at.\%) alloy. Similarly, a single $\beta$-phase was retained in the Ti-14Nb-30Zr (at.\%) alloy but not in the $\mathrm{Ti}-12 \mathrm{Nb}-30 \mathrm{Zr}$ (at.\%) alloy. Considering that $\mathrm{Nb}$ and $\mathrm{Zr}$ are generally weak $\beta$-stabilizers, it can be assumed that the Mo-Eq values of the Ti-Nb-Zr alloys listed in Table I are all in the vicinity of the critical value, i.e., 10 wt.\%. Consequently, the $\beta$-stabilizing effect of $\mathrm{Zr}$ in these Ti-Nb-Zr alloys can be estimated by the quantity, $\Delta=10-\psi \times \mathrm{Nb}$ (wt.\%). Figure 1 shows the dependence of the quantity, $\Delta=10-\psi \times$ $\mathrm{Nb}$ (wt.\%), on the $\mathrm{Zr}$ content for all the $\mathrm{Ti}-\mathrm{Nb}-\mathrm{Zr}$ alloys listed in Table I. The resultant significant linear relationship identifies the contribution of $\mathrm{Zr}$ in stabilizing the $\beta$ phase in Ti-Nb-Zr alloys considered in Table I. Accordingly, a new Mo-Eq for Ti-Nb-Zr alloys can be defined from Fig. 1 as

$$
(\mathrm{Mo}-\mathrm{Eq})_{\mathrm{Ti}-\mathrm{Nb}-\mathrm{Zr}}=0.238 \mathrm{Nb}(\text { wt. } \%)+0.11 \mathrm{Zr}(\mathrm{wt} . \%)+0.97
$$

Equation 7 was applied to all the Ti-Nb-Zr alloys listed in Table I. Good consistency was observed with the experimental observations, where, when the new Mo-Eq parameter is close to or above 10, the alloy contains $\beta$-phase as the primary phase (along with some other secondary phases) after water quenching, while, when it is clearly below 10 , martensite is the dominant phase.

\section{APPLYING THE NEW MO-EQ TO THE DESIGN OF TI-NB-ZR ALLOYS AND VALIDATION}

Table II summarizes the Mo-Eq values predicted by Eqs. 2-5 and 7 for six newly designed Ti-Nb-Zr alloys in this study (the first six alloys in Table II) and those available in the literature. Ingot samples of these alloys were made by arc-melting of a mixture of pure metals (purity $>99.9$ wt.\%) in a Ti-gettered high-purity argon atmosphere. The ingots were remelted four times to ensure chemical homogeneity. Then, the melted alloys were cast into a copper mold with a cylindrical cavity of $10 \mathrm{~mm}$ in diameter and $60 \mathrm{~mm}$ in depth. The as-cast samples with a diameter of $10 \mathrm{~mm}$ and thickness of $2 \mathrm{~mm}$ were homogenized at $1000^{\circ} \mathrm{C}$ for $4 \mathrm{~h}$ and then solution-treated at $900^{\circ} \mathrm{C}$ for $0.5 \mathrm{~h}$, followed by water quenching. Samples were ground with $\mathrm{SiC}$ grinding papers of up to 4000 grit for microstructural characterization. Final polish was performed with a mixture of colloidal silica and $\mathrm{H}_{2} \mathrm{O}_{2}$. The samples were subsequently cleaned in an ultrasonic bath using ethanol and etched with Kroll's reagent. Phase identification was conducted using a Bruker D8 Advance x-ray diffractometer (XRD) with a $\mathrm{Cu} \mathrm{K}_{\alpha}$ radiation source at room temperature, and the resultant XRD data was analyzed by MAUD software.

Figure 2 shows the XRD data of six waterquenched $\mathrm{Ti}-\mathrm{Nb}-\mathrm{Zr}$ alloys and optical micrographs of two of them. Ti-10Nb-26Zr (at.\%) was predicted to have martensite due to its low Mo-Eq (8.6, 
Table II. Newly designed metastable Ti-Nb-Zr alloys and corresponding Mo-Eq values

\begin{tabular}{|c|c|c|c|c|c|c|c|}
\hline \multirow[b]{2}{*}{ References } & \multicolumn{2}{|c|}{ Alloy compositions } & \multicolumn{5}{|c|}{ Mo-Eq values by different expressions } \\
\hline & at.\% & wt.\% & $\begin{array}{c}\text { Equation } \\
\mathbf{2} \\
\end{array}$ & $\begin{array}{c}\text { Equation } \\
\mathbf{3} \\
\end{array}$ & $\begin{array}{c}\text { Equation } \\
4 \\
\end{array}$ & $\begin{array}{c}\text { Equation } \\
\mathbf{5} \\
\end{array}$ & $\begin{array}{c}\text { Equation } \\
7 \\
\end{array}$ \\
\hline $\begin{array}{l}\text { Zr-based alloys } \\
\text { (this study) }\end{array}$ & $\begin{array}{l}\text { Ti-15Nb-40Zr } \\
\text { Ti-10Nb-55Zr }\end{array}$ & $\begin{array}{l}\text { Ti-19.3Nb-50.7Zr } \\
\text { Ti-12.2Nb-65.8Zr }\end{array}$ & $\begin{array}{l}5.44 \\
3.42\end{array}$ & $\begin{array}{l}7.53 \\
4.76\end{array}$ & $\begin{array}{l}5.98 \\
3.78\end{array}$ & $\begin{array}{l}29.23 \\
34.34\end{array}$ & $\begin{array}{l}11.1 \\
11.1\end{array}$ \\
\hline $\begin{array}{l}\text { Ti-based alloys } \\
\text { (this study) }\end{array}$ & $\begin{array}{l}\text { Ti-10Nb-26Zr } \\
\text { Ti-15Nb-25Zr } \\
\text { Ti-15Nb-22Zr } \\
\text { Ti-20Nb-21Zr }\end{array}$ & $\begin{array}{l}\text { Ti-15Nb-37Zr } \\
\text { Ti-21.3Nb-34.8Zr } \\
\text { Ti-22Nb-31.3Zr } \\
\text { Ti-28Nb-29Zr }\end{array}$ & $\begin{array}{l}4.2 \\
5.96 \\
6.16 \\
7.84\end{array}$ & $\begin{array}{r}5.85 \\
8.31 \\
8.58 \\
10.92\end{array}$ & $\begin{array}{l}4.65 \\
6.6 \\
6.82 \\
8.68\end{array}$ & $\begin{array}{l}21.59 \\
22.32 \\
20.87 \\
21.47\end{array}$ & $\begin{array}{c}8.6 \\
9.9 \\
9.6 \\
10.8\end{array}$ \\
\hline 13 & $\begin{array}{l}\text { Ti-24.5Nb-18.3Zr } \\
\text { Ti-22Nb-24Zr } \\
\text { Ti-20.7Nb-26.7Zr } \\
\text { Ti-18.6Nb-31.1Zr }\end{array}$ & $\begin{array}{l}\text { Ti-34Nb-25Zr } \\
\text { Ti-30Nb-32Zr } \\
\text { Ti-28Nb-35.4Zr } \\
\text { Ti-24.8Nb-40.7Zr }\end{array}$ & $\begin{array}{l}9.52 \\
8.4 \\
7.84 \\
6.94\end{array}$ & $\begin{array}{l}13.26 \\
11.7 \\
10.92 \\
9.67\end{array}$ & $\begin{array}{c}10.54 \\
9.3 \\
8.68 \\
7.69\end{array}$ & $\begin{array}{l}21.27 \\
23.44 \\
24.48 \\
26.07\end{array}$ & $\begin{array}{l}11.8 \\
11.6 \\
11.5 \\
11.3\end{array}$ \\
\hline 14 & $\begin{array}{l}\text { Ti-20Nb-12Zr } \\
\text { Ti-17Nb-21Zr } \\
\text { Ti-11Nb-38Zr } \\
\text { Ti-6Nb-53Zr }\end{array}$ & $\begin{array}{l}\text { Ti-29.9Nb-17.6Zr } \\
\text { Ti-24.4Nb-29.6Zr } \\
\text { Ti-14.7Nb-50Zr } \\
\text { Ti-7.6Nb-65.7Zr }\end{array}$ & $\begin{array}{l}8.4 \\
6.72 \\
4.2 \\
2.24\end{array}$ & $\begin{array}{r}11.7 \\
9.36 \\
5.85 \\
3.12\end{array}$ & $\begin{array}{l}9.3 \\
7.44 \\
4.65 \\
2.48\end{array}$ & $\begin{array}{l}16.86 \\
20.82 \\
27.7 \\
32.79\end{array}$ & $\begin{array}{l}10 \\
10 \\
10 \\
10\end{array}$ \\
\hline 15 & $\mathrm{Ti}-22.6 \mathrm{Nb}-4.6 \mathrm{Zr}$ & $\mathrm{Ti}-35 \mathrm{Nb}-7 \mathrm{Zr}$ & 9.8 & 13.65 & 10.85 & 13.09 & 10 \\
\hline
\end{tabular}

Table II) while the rest should essentially be single $\beta$-phase in the water-quenched state. Both the XRD data and microstructural observations have confirmed these predictions, where the $\beta$-phase is predominant in each of the other five alloys (e.g., Figure 2c) plus a small amount of secondary phases $\left(\alpha^{\prime \prime}, \omega\right)$ while Ti-10Nb-26Zr (at.\%) contains significant $\alpha^{\prime \prime}$-martensite (Fig. $2 \mathrm{~d}$ ). The newly defined Mo-Eq expression by Eq. 7 is in good agreement with the experimental observations of each alloy.

With regard to the alloys from the literature (Table II), they were all reported to be nearly single $\beta$-phase alloys (i.e., may contain a small amount of $\alpha^{\prime \prime}$ and/or $\left.\omega\right)^{13-15}$ By the definition of the Mo-Eq, their Mo-Eq values should be equal to or above 10 wt.\%. As can be seen from Table II, the new MoEq (Eq. 7) also shows excellent consistency with experimental observations.

\section{THE NEWLY PROPOSED MO-EQ AND THE D-ELECTRON THEORY}

The $d$-electron theory describes the potential relationship between phase stability and elastic properties of $\mathrm{Ti}$ alloys through two electronic properties, bond order, $B_{\mathrm{o}}$ and $d$-orbital energy level, $M_{d} \cdot{ }^{12,16}$ It was developed by Morinaga ${ }^{16}$ on the basis of the DV-X $\alpha$ molecular orbital calculations of electronic structures. The theory has become an essential fundamental tool for the design of $\beta-\mathrm{Ti}$ alloys. ${ }^{1,12}$ In this approach, $B_{\mathrm{o}}$ denotes the covalent bond strength between $\mathrm{Ti}$ and a specific alloying element and $M_{d}$ correlates the electronegativity and metallic radius of that element. $B_{\mathrm{o}}$ and $M_{d}$ values for all the alloying elements of $\mathrm{Ti}$ can be found in Ref. 16. Using these $B_{0}$ and $M_{d}$ values, the compositional average of $B_{\mathrm{o}}$ and $M_{d}$ can be calculated based on alloy composition through the following equations. ${ }^{16}$

$$
\begin{gathered}
\overline{B_{\mathrm{o}}}=\sum X_{i}\left(B_{\mathrm{o}}\right)_{i} \\
\overline{M_{d}}=\sum X_{i}\left(M_{d}\right)_{i}
\end{gathered}
$$

where $X_{i},\left(B_{\mathrm{o}}\right)_{i}$ and $\left(M_{d}\right)_{i}$ are the atomic fraction, bond order and $d$-orbital energy level of the given element, respectively. Then, a $\overline{B_{0}}-\overline{M_{d}}$ diagram can be plotted by taking the $\overline{B_{0}}$ and $\overline{M_{d}}$ values of different Ti alloys. Several sets of Ti alloys are used to define the three regions, $\alpha, \alpha+\beta$, $\beta$, of this $\overline{B_{0}}-\overline{M_{d}}$ diagram. Along the $(\alpha+\beta) / \beta$ boundary in the $\overline{B_{0}}-\overline{M_{d}}$ diagram, the $\beta$-phase is considered metastable.

Figure 3 shows the $\overline{B_{0}}-\overline{M_{d}}$ diagram plotted for this study on the basis of Refs. 12 and 14. A triangle is drawn by connecting the $B_{\mathrm{o}}$ and $M_{d}$ values for pure $\mathrm{Ti}, \mathrm{Nb}$ and $\mathrm{Zr}$, which define the regime of the Ti-Nb-Zr alloys, similar to ternary phase diagrams. Each side of this triangle indicates the compositional average values of $B_{\mathrm{o}}$ and $M_{d}$ of the Ti-Nb, Ti$\mathrm{Zr}$ and $\mathrm{Zr}-\mathrm{Nb}$ binary alloys. The blue dotted line represents the boundary of critical compositions for metastable $\beta$ alloys according to the inventor of the $d$-electron theory. ${ }^{12}$ This boundary may shift upwards or downwards depending on the exact alloying compositions. In the $\mathrm{Ti}-\mathrm{Nb}-\mathrm{Zr}$ system, adding $\mathrm{Zr}$ was found to shift this boundary downwards, ${ }^{14}$ as shown by the black dashed line in Fig. 3. The Mo-Eq values predicted by Eq. 7 are superimposed onto Fig. 3, which indicates that the newly developed Mo-Eq expression is also in good agreement with the $d$-electron theory in predicting the 
(a)

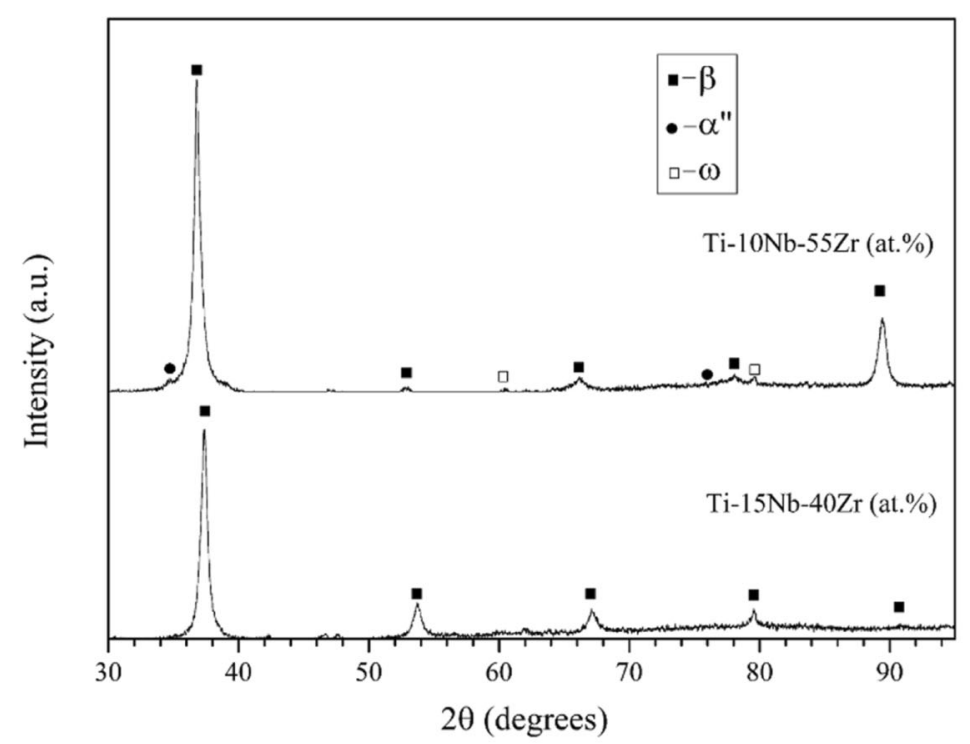

(b)
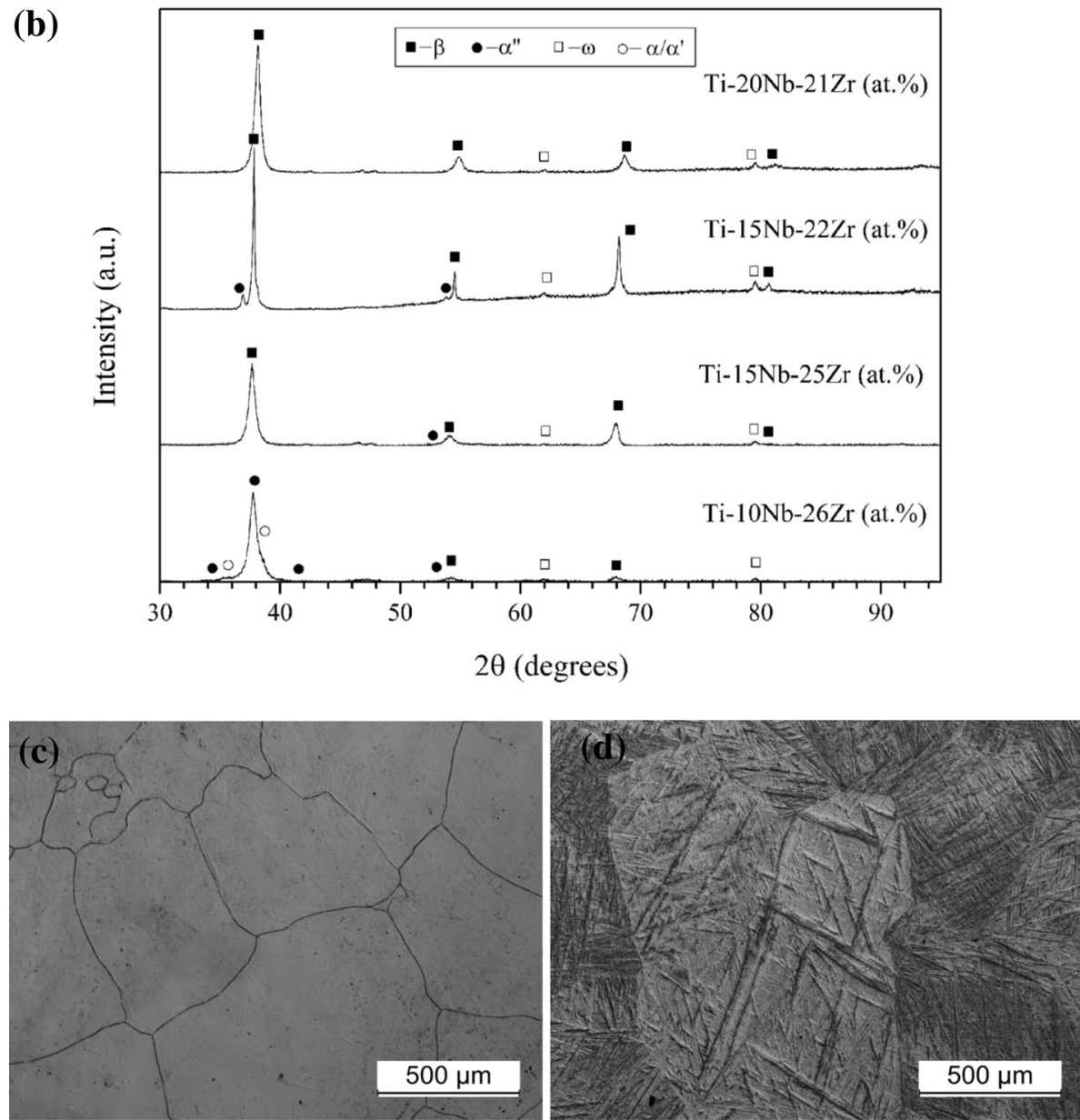

Fig. 2. XRD results of (a) two Zr-based Ti-Nb-Zr alloys and (b) four Ti-based Ti-Nb-Zr alloys. (c) Water-quenched Ti-15Nb-40Zr (at.\%), nearly single $\beta$. (d) Water-quenched Ti-10Nb-26Zr (at.\%), noticeable $\alpha^{\prime \prime}$-martensite.

$\beta$-phase stability. For example, Ti-Nb-Zr alloys having Mo-Eq values higher than $10 \mathrm{wt} . \%$ are situated above the black dashed line and vice versa.
The new Mo-Eq is thus consistent with the $d$ electron theory for $\mathrm{Ti}-\mathrm{Nb}-\mathrm{Zr}$ alloys, which was not the case for all the other four Mo-Eq expressions. 


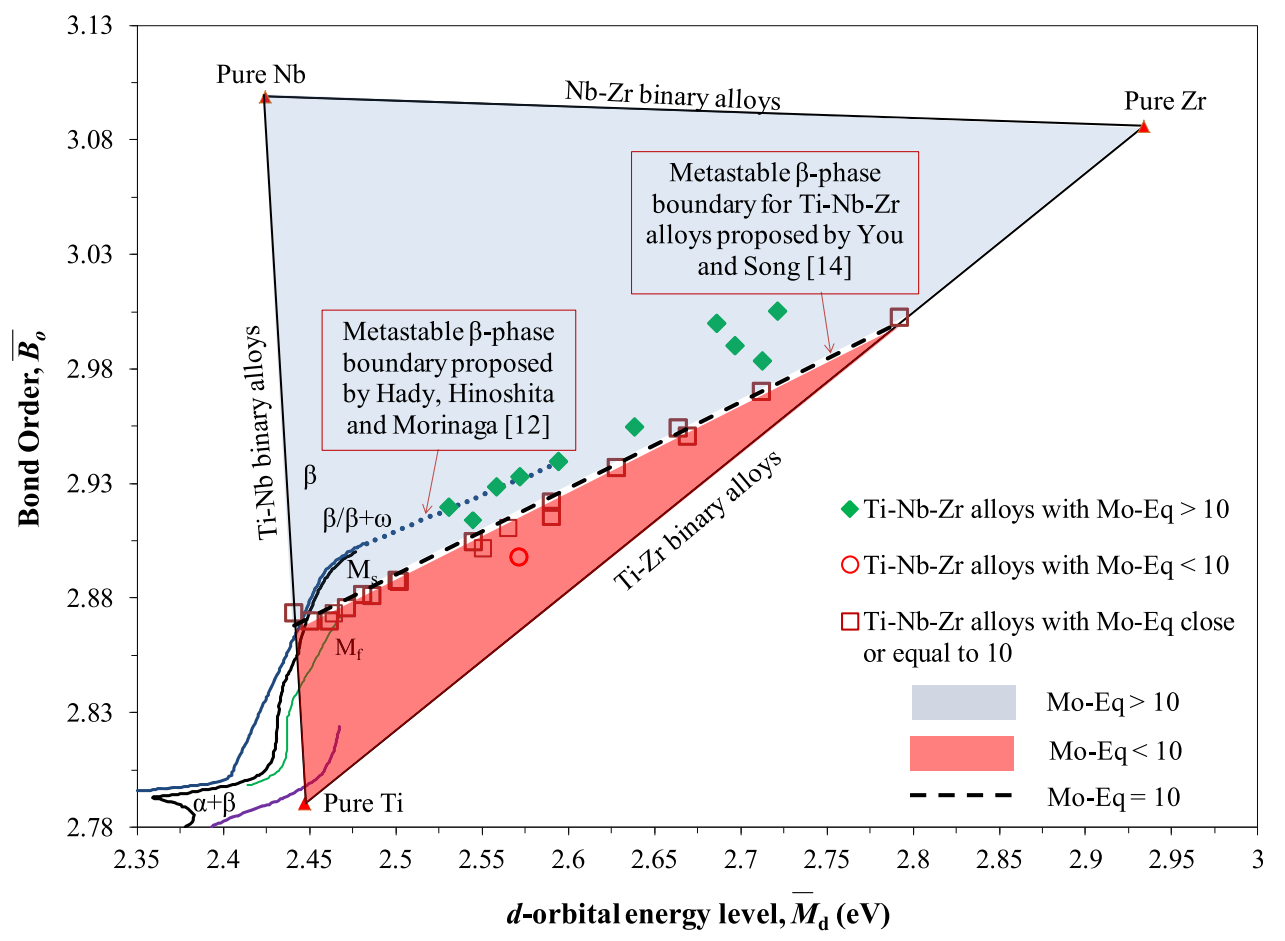

Fig. 3. Ti-Nb-Zr alloys in the $\overline{B_{0}}-\overline{M_{\mathrm{d}}}$ map. $^{13-16}$

\section{SUMMARY}

A new Mo-Eq expression has been formulated for the Ti-Nb-Zr system, i.e., $(\mathrm{Mo}-\mathrm{Eq})_{\mathrm{Ti}-\mathrm{Nb}-\mathrm{Zr}}=$ $0.238 \mathrm{Nb} \quad($ wt. $\%)+0.11 \mathrm{Zr} \quad($ wt. $\%)+0.97$, which shows good consistency with experimental observations as well as literature data. In addition, it is highly consistent with the well-established $d$-electron theory in predicting the $\beta$-phase stability of various $\mathrm{Ti}-\mathrm{Nb}-\mathrm{Zr}$ alloys. In contrast, none of the existing four Mo-Eq expressions is consistent with the $d$-electron theory, as well as experimental observations. However, caution should be exercised when the alloy composition goes significantly beyond the bounds of the chemistries discussed in this study. It is proposed that the approach developed in this work can also be applied to the assessment of the $\beta$-phase stability in other Zr-containing Ti alloys.

\section{ACKNOWLEDGEMENTS}

This work was supported by the Australian Research Council (ARC) through DP150104719. The authors are grateful to Rodney Boyer for drawing our attention to E. K. Molchanova's original contribution to the concept of the Mo equivalence (see Ref. 3).

\section{REFERENCES}

1. I.J. Polmear, D.H. StJohn, J.F. Nie, and M. Qian, Light Alloys: Metallurgy of Light Metals, 5th ed. (Waltham, MA: Butterworth-Heinemann, 2017).

2. I. Weiss and S. Semiatin, Mater. Sci. Eng. A 243, 46 (1998).

3. E.K. Molchanova and S. Glazunov, Phase Diagrams of Titanium Alloys: Transl. by A. Halbreich, N. Kaner, M. Statter, (Israel Program for Scientific Translation, 1965).

4. R. Boyer, G. Welsch, and E. Collings, Materials properties handbook: titanium alloys (Metals Park, OH: ASM international, 1994).

5. P.J. Bania, JOM 46, 16 (1994).

6. Y.B. Zhou, Titanium Alloy Casting (Beijing: Aviation Industry Press, 2000).

7. M. Wei, eds., Titanium (Beijing: China Metallurgical Industry Press, 2008).

8. Q. Wang, C. Dong, and P.K. Liaw, Metall. Trans. A 46, 3440 (2015).

9. M. Abdel-Hady, H. Fuwa, K. Hinoshita, H. Kimura, Y. Shinzato, and M. Morinaga, Scr. Mater. 57, 1000 (2007).

10. Y. Li, Z. Ru, Y. Cui, and K. Luo, Int. J. Smart Nano Mater. 2, 272 (2011).

11. J. Kim, H. Kim, T. Inamura, H. Hosoda, and S. Miyazaki, Mater. Sci. Eng. A 403, 334 (2005).

12. M. Abdel-Hady, K. Hinoshita, and M. Morinaga, Scr. Mater. 55, 477 (2006).

13. S. Ozan, J. Lin, Y. Li, R. Ipek, and C. Wen, Acta Biomater. 20, 176 (2015).

14. L. You and X. Song, Scr. Mater. 67, 57 (2012).

15. J. Chaves, O. Florêncio, P. Silva, P. Marques, and S. Schneider, J. Alloys Compd 616, 420 (2014).

16. M. Morinaga and H. Yukawa, Bull. Mater. Sci. 20, 805 (1997). 